\title{
Metabolic insights in Arctic charr (Salvelinus alpinus) fed with zygomycetes and fish meal diets as assessed in liver using nuclear magnetic resonance (NMR) spectroscopy
}

\author{
Rani Abro • Ali Ata Moazzami · Jan Erik Lindberg • \\ Torbjörn Lundh
}

Received: 18 December 2013/Accepted: 22 May 2014/Published online: 6 June 2014

(C) The Author(s) 2014. This article is published with open access at Springerlink.com

\begin{abstract}
Fish meal is the major source of animal protein in feed for cultured salmonid fish, but its availability is limited and it must eventually be replaced by alternative protein-rich feed ingredients. Zygomycetes (Rhizopus oryzae) is a fungus with protein-rich biomass that could replace fish meal protein in fish feed. Using an ${ }^{1} \mathrm{H}$ NMR spectroscopy approach, we studied the metabolic pattern in liver tissues of Arctic charr (Salvelinus alpinus) fed a commercial diet with unknown composition (ST), a diet with all protein from fish meal (FM) and a diet with most of the protein from zygomycetes biomass (FZ). No significant difference $(p \geq 0.05)$ was found in spectral data between FM and FZ using the OPLS-DA fitted model. However, other models showed that diet ST clearly differed $(p<0.05)$ from diets FM and FZ. Signals for acetate, $\beta$-alanine, choline, creatine, formate, glucose, inosine, lysine, $\mathrm{SN}$-glycero-3-phosphocholine and two unknown metabolites were higher in fish fed diets FM and FZ than in fish fed diet ST. These results show that the metabolic profile in liver of Arctic charr will remain unchanged if fish meal protein is replaced with zygomycete protein, suggesting similar physiological responses to both feed ingredients. In contrast, feeding a commercial diet altered the metabolic fingerprint compared with diets FZ and FM, suggesting important differences in ingredient composition and the physiological response to this diet.
\end{abstract}

Keywords Arctic charr $\cdot$ Metabolomics $\cdot$ NMR $\cdot$ Metabolites $\cdot$ Zygomycetes $\cdot$ Fish meal $\cdot$ Diets $\cdot$ Fish

\section{Introduction}

Fish meal constitutes the major source of animal protein in commercial feed for cultured salmonid fish (Sargent and Tacon 1999). However, the availability of fish meal derived from marine fish is limited (Barlow 2000; Tacon 2004). Moreover, the use of fish meal in fish feed is not a sustainable long-term feeding strategy. Therefore, alternative sources of protein that can be used to replace fish meal need to be explored. This is an essential prerequisite in establishing sustainable fish farming (Kristofersson and Anderson 2006).

Zygomycetes (Rhizopus oryzae) is a microfungus with biomass that is rich in protein and may have the potential to replace fish meal in fish feed (Edebo 2009). In addition to protein, the fungal biomass is rich in

R. Abro · J. E. Lindberg · T. Lundh ( $₫)$

Department of Animal Nutrition and Management, Swedish University of Agricultural Sciences, P.O. Box 7024,

75007 Uppsala, Sweden

e-mail: Torbjorn.lundh@slu.se

A. A. Moazzami

Department of Chemistry and Biotechnology, Uppsala BioCenter, Swedish University of Agricultural Sciences,

P.O. Box 7015, 75007 Uppsala, Sweden 
carbohydrates (Sues et al. 2005). The carbohydrate fraction is made up of chitin/chitosan heteropolysaccharides, which can vary in content (45-85\%) depending upon fungal strain and cultivation conditions (Zamani 2010). Zygomycetes has been widely used for food production and for production of different organic substances and extra-cellular enzymes (Sues et al. 2005; Dijksterhuis and Samson 2006).

Metabolomics has emerged as a promising novel tool to obtain detailed insights into the impact of nutrition on the metabolic response in animals and humans (Bankefors et al. 2011; Gibney et al. 2005; Brennan 2013). The technique allows rapid identification in biological samples of key metabolites that can be related to nutritional interventions (Moco et al. 2006; Wishart et al. 2007) and provides information that cannot be achieved with more conventional approaches. The proton nuclear magnetic resonance (NMR) technology has been applied extensively in the field of metabolomics in food science research to assess physiological and biological responses to various food items and diets, e.g. chamomile tea (Wang et al. 2005), whole-grain flour (WGF) and refined wheat flour (RF) (Fardet et al. 2007),vegetarian, low-meat and high-meat diets (Stella et al. 2006), and vitamin supplementation (Griffin et al. 2002). The technique has also been successfully applied to determine the biochemical effects of bioactive compounds and the metabolic profile in individuals fed a variety of diets, using organ extracts from different organs (e.g. liver, kidney, stomach, intestine) (Waters et al. 2002; Mun et al. 2004; Ramadan et al. 2005; Serkova et al. 2005).

Liver is the most metabolically active organ. The liver of the fish is involved in metabolism of absorbed nutrients, export of substrates (amino acids, fatty acids, carbohydrates) and synthesis of essential macromolecules (Bystriansky et al. 2007). The aim of the present study was to compare biochemical effects and metabolic profile in the liver of Arctic charr fed a fish meal-based diet (FM), a zygomycete-based diet (FZ), and a commercial diet (ST) using an ${ }^{1} \mathrm{H}$ NMR spectroscopy approach. Our working hypothesis was that the metabolic fingerprint of feeding diets FM and FZ would be similar due to their comparable nutrient profiles. Thus, we assumed that zygomycete protein could replace fish meal protein with maintained physiological and metabolic effects. Moreover, we hypothesised that the commercial diet would result in a different metabolic fingerprint from diet FM due to inclusion of other (unknown) feed ingredients.

\section{Materials and methods}

Fish rearing

Arctic char (Salvelinus alpinus) fingerlings with an initial body weight of $95 \pm 22 \mathrm{~g}$ were reared at the Aquaculture Centre North in Kälarne, Sweden. The experimental diets were fed to three replicate groups of fish in flow through fibreglass tanks $\left(1 \mathrm{~m}^{3}\right)$, with 6 fish per tank. During the experiment, water temperature was maintained at $4-6{ }^{\circ} \mathrm{C}$. The water flow was approximately $15 \mathrm{~L} \mathrm{~min}{ }^{-1}$. Dissolved oxygen was maintained in a controlled system with oxygen meters recording the inlet water. The fish were fed twice daily, by using belt feeders, with a total daily allowance of $2 \%$ of body weight, during the 4-week experiment. The fish accepted the experimental diets and no mortality was observed during the experiment. Fish weight was recorded at the beginning and end of the experiment, in order to confirm that the fish had consumed the test diets and had a positive energy balance. The fish gain in weight on all diets, with the highest value for the ST and FM diet and less on the FZ diet, with a mean weight gain of 69.1, 59.2 and $14.1 \mathrm{~g}$, respectively. The experiment was approved by the Ethical Committee for Animal Experiments in the Umeå region.

Diets

The fish were fed a commercial diet for salmonid fish (diet ST) with unknown composition, a diet with fish meal providing the majority of the protein (diet FM) and a diet with zygomycetes biomass providing the majority of the protein (diet FZ) (Table 1). The ingredients for diets FM and FZ were thoroughly mixed to a stiff dough and pelleted using a meat grinder (MR9-TC22, Nima maskinteknik AB, Örebro, Sweden) with a 2-mm die. The pelleted feed strings were dried and chopped to pellets of approximately $2 \mathrm{~mm}$ length. 
Table 1 Composition and proximate analyses of the diets based on fish meal (FM) and zygomycete meal (FZ) and the commercial diet (ST) (g/kg dry weight)

\begin{tabular}{lrrr}
\hline Ingredients & Diets & & \\
\cline { 2 - 4 } & FM & FZ & ST \\
\hline Fish meal & 580 & 230 & $\mathrm{n}$ \\
Fish oil & 130 & 130 & $\mathrm{n}$ \\
Rapeseed oil & 70 & 70 & $\mathrm{n}$ \\
Zygomycete biomass & 0 & 480 & $\mathrm{n}$ \\
Wheat & 80 & 0 & $\mathrm{n}$ \\
Gelatin & 65 & 65 & $\mathrm{n}$ \\
Mineral/vitamin mix & 10 & 10 & $\mathrm{n}$ \\
Titanium dioxide & 5 & 5 & $\mathrm{n}$ \\
Proximate analysis & & & 531 \\
Crude protein & 489 & 471 & 221 \\
Crude fat & 244 & 178 & 89 \\
Ash & 96 & 95 & \\
\hline
\end{tabular}

$n$ no information available

Chemical analysis

Samples of feed ingredients and diets were analysed using standard methods (AOAC 1997). Dry matter was determined by drying in an oven at $105{ }^{\circ} \mathrm{C}$ for $24 \mathrm{~h}$. Nitrogen $(\mathrm{N})$ was determined by the Kjeldahl method and crude protein $(\mathrm{CP})$ was calculated as $N \times 6.25$. Crude fat (EE) content was analysed using the Soxhlet method after acid hydrolysis of the sample. Ash content was determined by incineration in a muffle furnace at $550{ }^{\circ} \mathrm{C}$ for $12 \mathrm{~h}$. Gross energy $\left(\mathrm{MJ} \mathrm{kg}^{-1}\right.$ ) was determined with a bomb calorimeter (Calorimeter Parr 6300, Parr Instrument Company, Moline, IL, USA). Amino acid content in the feed was analysed using the Waters AccQ $\mathrm{Tag}^{\mathrm{TM}}$ method. In brief, $50 \mathrm{mg}$ feed samples were weighed into a $100 \mathrm{~mL}$ Teflon liner for a Paar microwave oven. The samples were hydrolysed in $15 \mathrm{~mL} 6 \mathrm{M} \mathrm{HCl}$ containing $1 \%$ phenol in a microwave oven (Synthos 3000, Anton Paar Nordic AB, Sweden). The temperature programme for the microwave oven was set to increase to $150{ }^{\circ} \mathrm{C}$ during $5 \mathrm{~min}$, this temperature was held for $30 \mathrm{~min}$ and cooled for $15 \mathrm{~min}$. For analysis of methionine and cysteine, $50 \mathrm{mg}$ feed samples were added to $2 \mathrm{~mL}$ cold, freshly prepared formic acid:perhydrol $(9: 1)$ and incubated overnight at $+4{ }^{\circ} \mathrm{C}$. Thereafter, $2 \mathrm{~mL}$ freshly prepared sodium bisulphite $(0.17 \mathrm{~g}$ sodium bisulphite $/ \mathrm{mL}$ water) solution were added to each tube and the contents mixed for $15 \mathrm{~min}$. The samples were then hydrolysed as described above.

The hydrolysed samples were neutralised, diluted and derivatised according to the WatersUPLC ${ }^{\circledR}$ amino acid analysis solution protocol. The UPLC system was a Dionex, Ultimate 3000 binary rapid separation LC system with a variable UV-detector (Thermo Fisher, Sweden, Stockholm). Empower 2 (Waters) software was used for system control and data acquisition.

Extraction and sample preparation for NMR analysis

Four fish from each tank (12 per treatment) were collected and anesthetised with Tricane methane sulphonate (MS-222) solution $(50 \mathrm{mg} / \mathrm{L})$. Liver tissues were dissected from the fish and immediately transferred into liquid nitrogen. All the liver tissues were kept frozen at $-80{ }^{\circ} \mathrm{C}$ for further NMR analyses. Sample preparation was carried out with modifications as previously reported (Atherton et al. 2006; Moazzami et al. 2011). Liver tissue portions (100 mg from the right side of the ventral lobe) were added to $3 \mathrm{~mL}$ ice-cold methanolchloroform (2:1) and the mixture was homogenised for $1 \mathrm{~min}$ in a homogeniser (HeidolphDiax, Schwabach, Germany). The mixture was then subjected to sonication for $40 \mathrm{~min}$, followed by vortex mixing every $10 \mathrm{~min}$. A $1 \mathrm{~mL}$ portion each of ice-cold water and chloroform were added and the mixture was vortexed again for $1 \mathrm{~min}$ and centrifuged at 2,800 $\mathrm{g}$ for $30 \mathrm{~min}$. The supernatant (water phase) was collected and transferred to new tubes. The volume was adjusted to a similar level in each tube and the contents were then dried using an 
evacuated centrifuge (Savant, SVC 100H, Savant Instruments INC, New York, NJ, USA). The dried pellet was dissolved in $520 \mu \mathrm{L}$ sodium phosphate buffer $(0.25 \mathrm{M}, \mathrm{pH} 7.0), 50 \mu \mathrm{L} \mathrm{D}_{2} \mathrm{O}$ and $30 \mu \mathrm{L}$ (internal standard) $1 \mathrm{mM}$ sodium-3-(trimethylsilyl)-2,2,3,3-tetradeuteriopropionate (Cambridge Isotope Laboratories, Andover, MA, USA). Finally, $500 \mu \mathrm{L}$ portions of reconstituted mixture were transferred to NMR tubes for further NMR analysis.

NMR spectroscopy analysis

The NMR spectra of liver tissue extracts were obtained using a Bruker AV 400 NMR spectrometer (Karlsruhe, Germany) equipped with a $5 \mathrm{~mm}$ inverse broadband probe. The NMR spectra were obtained at $25{ }^{\circ} \mathrm{C}$ with 264 scans and 32,764 data points, with a spectral width of $8,012.82 \mathrm{~Hz}$. The acquisition time was $2 \mathrm{~s}$ and the relaxation delay was $3.0 \mathrm{~s}$. The one-dimensional ${ }^{1} \mathrm{H}$ NMR spectra with water pre-saturation were recorded using Noesypr1D (Bruker, BioSpin, Karlsruhe, Germany).

NMR spectral data were processed using Bruker Topspin 1.3 software, Fourier-transformed after multiplication by a line broadening of $0.3 \mathrm{~Hz}$ and referenced to TSP [sodium-3-(trimethylsilyl)-2,2,3,3-tetradeuteriopropionate] at $0.0 \mathrm{ppm}$. The spectral phase and baseline were manually corrected. Each ${ }^{1} \mathrm{H}$ NMR spectrum was integrated using Amix 3.7.3 (BrukerBioSpin) into $0.01 \mathrm{ppm}$ integral regions (buckets) between 0.5 and $8.55 \mathrm{ppm}$. The region spanning $4.41-5.39 \mathrm{ppm}$ containing residual water was removed. Each spectral region was normalised to the intensity of the internal standard (TSP).

The ${ }^{1}$ HNMR signals were identified using the ChenomX software library (ChenomX Inc., Canada), Biological Magnetic Resonance Data Bank (http://www.bmrb.wisc.edu) and the Human Metabolome Database (HMD) (http://www.hmdb.ca).

Spectral pre-processing and statistical analyses

Nuclear magnetic resonance spectral data were collected and analysed using SIMCA-P+ 12.0.1 software (UME-TRICS, Umeå, Sweden). The data sets were centred and pareto-scaled before statistical analysis with principal component analysis (PCA) and orthogonal partial least squares-discriminate analysis (OPLS-DA). The PCA model was used to look for outliers and to identify any clustering pattern with regard to the different diets. The outliers were determined using PCA-Hotelling $T^{2}$ Ellipse $(95 \% \mathrm{CI})$. The normality of multivariate data was tested using probability plot of PCA model. PCA models including all three diets or two diets at a time were fitted (FM vs. FZ, FM vs. ST, and FZ vs. ST).

The OPLS-DA model was fitted in order to look for the discriminating metabolites in the profile of liver metabolites in response to different diets. Variable influence on projection (VIP) of the NMR spectral regions was used to identify the discriminative metabolites between control and treatment diets. OPLS-DA models including all three diets or two diets at a time were fitted (FM vs. FZ, FM vs. ST, and FZ vs. ST). The NMR spectral regions with VIP $\geq 1$ outside the confidence interval or close to zero were considered different between different treatments.

The significance of the OPLS-DA model was tested using cross-validated ANOVA (CV-ANOVA), which is a diagnostic tool for assessing the reliability of OPLS models. The diagnostic is based on an ANOVA assessment of the cross-validatory predictive residuals of an OPLS-DA model. Cross-validated ANOVA tests whether the model has significantly smaller cross-validated predictive residuals than just the variation around the overall average (Eriksson et al. 2008).

\section{Results}

Principal component analysis

The PCA analysis was performed using the pre-processed ${ }^{1} \mathrm{H}$ NMR spectrum data obtained from liver tissue extracts of Arctic charr fed diets ST, FM and FZ. After excluding six outliers, the score scatter plot with first versus second components showed no apparent clustering difference with regard to different treatment diets (Fig. 1). Model parameters were: $R^{2} X$ component $1=0.56 ; R^{2} X$ component $2=0.13$. 
Fig. 1 Score plot of PCA model fitted using the metabolic profile in liver of Arctic charr fed diet FM (blue), diet FZ (green) and diet ST (red). Model parameters:

$R^{2} X$ component $1=0.56 ; R^{2} X$ component $2=0.13$

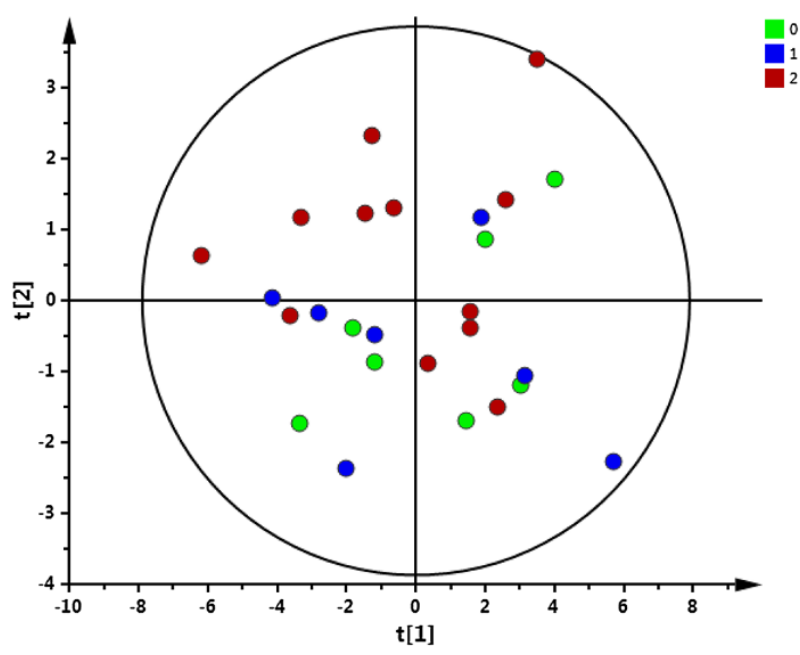

Orthogonal partial least squares discriminant analysis

In order to investigate differences in biochemical variations between the predefined classes of the diets, OPLSDA analysis was performed including all three diets. The OPLS-DA separated diets FM and FZ from diet ST along the first component. To obtain further insights regarding the biochemical differences between different diets, OPLS-DA models were fitted including just two diets at a time (FM vs. FZ, FM vs. ST, and FZ vs. ST). The OPLS-DA models fitted using spectral data for diets FM and FZ were not significantly different according to CV-ANOVA ( $p \geq 0.05$ ). However, the other models (FM vs. ST and FZ vs. ST) were significantly different $(p<0.05)$. In both OPLS-DA models, diet ST clearly differed from diets FM and FZ (Figs. 2, 3). Model parameters for FM vs. ST were: $R^{2} Y=0.98, Q^{2} Y=0.70$, cross-validated CV-ANOVA $p=0.042$ and five outliers were excluded based on the corresponding PCA-Hotelling $T^{2}$ Ellipse $(95 \% \mathrm{CI})$. Model parameters for FZ vs. ST were: $R^{2} Y=0.98, Q^{2} Y=0.73$, cross-validated ANOVA $p=0.014$ and two outliers were excluded based on the corresponding PCA-Hotelling $T^{2}$ Ellipse (95\% CI). Tables 2 and 3 show the metabolites which were found to be different when diets FM and FZ were compared with diet ST.

Identification of metabolites

The VIP plot and loading column plot of OPLS-DA were used to identify and compare differences in the metabolites of liver tissue extracts of Arctic charr fed diet FM vs. diet ST and diet FZ vs. diet ST. The spectral regions with VIP values $>1$ for the corresponding jack-knife-based confidence intervals not near to/or

Fig. 2 Score plot of OPLS-DA model fitted using the metabolic profile in liver of Arctic charr fed diet FM (left) and diet ST (right). The two diets are clearly separated along the first horizontal component. Model parameters: $R^{2} Y=0.98, Q^{2} Y=0.70$, cross-validated CV-ANOVA $p=0.042$. Five outliers were excluded based on corresponding PCA-Hotelling $T^{2}$ Ellipse $(95 \% \mathrm{CI})$

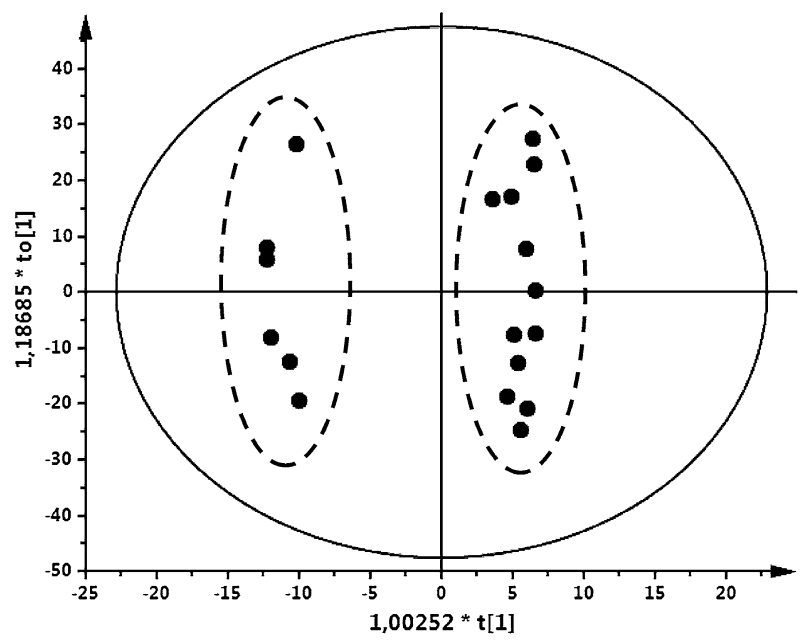


Fig. 3 Score plot of OPLS-DA model fitted using the metabolic profile in liver of Arctic charr fed diet FZ (left) and diet ST (right). The two diets are clearly separated along the first horizontal component. Model parameters: $R^{2} Y=0.98, Q^{2} Y=0.73$, cross-validated ANOVA $p=0.014$. Two outliers were excluded based on corresponding PCA-Hotelling $T^{2}$ Ellipse $(95 \% \mathrm{CI})$

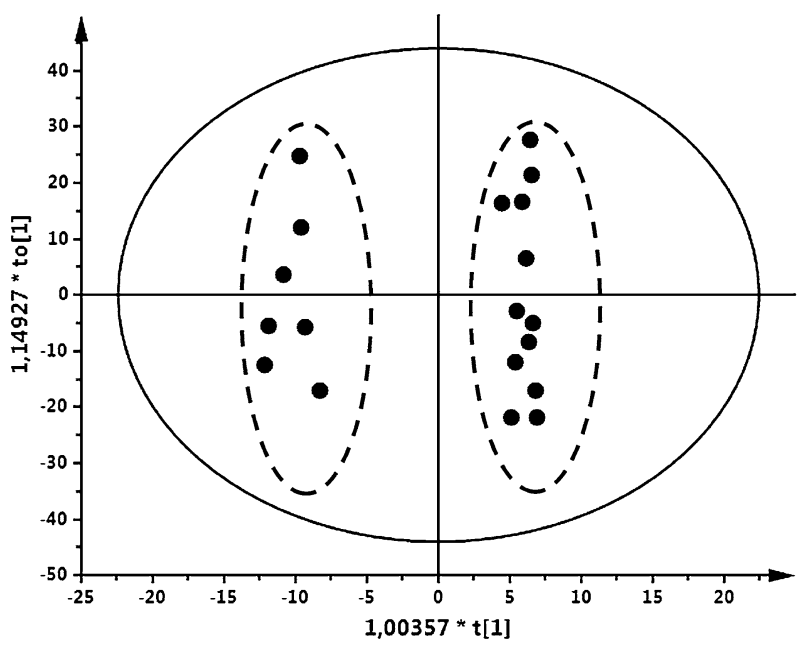

including zero were considered highly reliable and the corresponding compounds were selected as discriminative metabolites.

Metabolic analysis of diet FM vs. diet ST showed discrimination of various metabolites, i.e. acetate, asparagine, creatine, choline, SN-glycero-3-phosphocholine, formate and an unknown signal (Table 2). The levels of these metabolites were higher in fish fed diet FM than diet ST. However, asparagine was found at lower levels in fish fed diet FM than diet ST.

The effects of diet FZ vs. diet ST were apparent in the metabolites lysine, succinate, $\beta$-alanine, asparagine, creatine, SN-glycero-3-phosphocholine, glucose, inosine, formate and an unknown signal (Table 3). The data indicated that the levels of these metabolites were higher in fish fed diet FZ diet than diet ST. However, succinate and asparagine levels were lower in fish fed diet FZ than diet ST.

Amino acid profile

The levels of amino acids in the different diets are summarised in Table 4. The total amount of essential (EAA) and non-essential amino acids (NEAA) differed slightly between diets FM and ST (370 vs. $386 \mathrm{~g} / \mathrm{kg}$ diet). For diet FZ, the amino acid content (313 g/kg diet) was $19 \%$ lower than in diet ST. The sum of EAA was highest in diet ST $(180.6 \mathrm{~g} / \mathrm{kg})$, followed by diet FM $(158.2 \mathrm{~g} / \mathrm{kg})$ and diet FZ $(141.6 \mathrm{~g} / \mathrm{kg})$. The main differences were that histidine, leucine, phenylalanine and valine were all higher in diet ST than in diets FM and FZ. The highest content of NEAA was found in diet FM, which had higher contents of alanine, glycine and proline than diets FZ and ST.

Table 2 Assignment of ${ }^{1}$ HNMR spectrum for liver extract of Arctic charr fed the fish meal-based (FM) and commercial (ST) diets $(n=24)$

\begin{tabular}{llll}
\hline Metabolites & NMR signal $(\mathrm{PPm})^{\mathrm{a}}$ & Higher in & VIP $(\mathrm{CI})^{\mathrm{b}}$ \\
\hline Acetate & 1.925 & FM & $1.11(0.79)$ \\
Asparagine & $2.88,2.903,2.945$ & ST & $1.29(0.91), 1.27(0.89), 1.29(0.80)$ \\
Creatine & 3.032 & FM & $2.25(1.09)$ \\
Choline & 3.205 & FM & $1.72(1.38)$ \\
SN-glycero-3-phosphocholine & 3.232 & FM & $1.59(1.49)$ \\
Formate & 8.459 & FM & $1.78(0.67)$ \\
Unknown & 2.717 & FM & $2.72(1.59)$ \\
\hline
\end{tabular}

a The ${ }^{1}$ HNMR signal found to be discriminating along the first component of the OPLS-DA model clearly separated diet FZ from diet ST

b Spectral regions with VIP values $>1$ for the corresponding jack-knife-based confidence intervals not near to/or including zero were considered high reliability and the corresponding compounds selected as discriminative metabolites 
Table 3 Assignment of ${ }^{1}$ HNMR spectrum for liver extract of Arctic charr fed the zygomycete meal-based (FZ) and commercial (ST) diets $(n=24)$

\begin{tabular}{llll}
\hline Metabolite & NMR signal $(\mathrm{PPm})^{\mathrm{a}}$ & Higher in & VIP $(\mathrm{CI})^{\mathrm{b}}$ \\
\hline Lysine & $1.712,1.727,1.734$ & FZ & $1.26(0.91), 1.26(0.96), 1.31(0.90)$ \\
Succinate & 2.409 & ST & $1.73(1.48)$ \\
$\beta$-Alanine & $2.563,2.580$ & FZ & $1.29(0.68), 1.43(0.46)$ \\
Asparagine & $2.88,2.934,2.945$ & ST & $1.71(0.98), 1.73(0.95), 1.52(0.96)$ \\
Creatine & 3.032 & FZ & $1.54(0.88)$ \\
SN-glycero-3-phosphocholine & 3.231 & FZ & $1.94(1.68)$ \\
Glucose & $3.481,3.493,3.505$ & FZ & $1.60(0.95), 1.55(0.88), 1.63(1.01)$ \\
Inosine & $6.098,6.112,8.251$ & FZ & $1.91(0.61), 2.13(0.75), 1.92(0.73)$ \\
Formate & 8.459 & FZ & $2.20(0.65)$ \\
Unknown & 2.759 & FZ & $1.99(0.99)$ \\
\hline
\end{tabular}

${ }^{a}$ The ${ }^{1}$ HNMR signal found to be discriminating along the first component of the OPLS-DA model clearly separated diet FZ from diet ST

b Spectral regions with VIP values $>1$ for the corresponding jack-knife-based confidence intervals not near to/or including zero were considered high reliability and the corresponding compounds selected as discriminative metabolites

Table 4 Amino acid composition of the diets based on fish meal (FM) and zygomycete meal (FZ) and the commercial diet (ST) (g/kg dry matter)

\begin{tabular}{|c|c|c|c|}
\hline Amino acid & FM & $\mathrm{FZ}$ & ST \\
\hline \multicolumn{4}{|l|}{ Essential amino acids } \\
\hline Arginine & 24.8 & 21.2 & 25.4 \\
\hline Histidine & 7.7 & 6.6 & 14.6 \\
\hline Isoleucine & 13.3 & 14.8 & 12.4 \\
\hline Leucine & 28.3 & 24.6 & 36.2 \\
\hline Lysine & 28.8 & 25.3 & 27.9 \\
\hline Methionine-S & 14.8 & 14.0 & 11.7 \\
\hline Phenylalanine & 15.1 & 12.9 & 20.8 \\
\hline Threonine & 15.7 & 13.0 & 16.4 \\
\hline Valine & 18.3 & 18.7 & 22.8 \\
\hline \multicolumn{4}{|l|}{ Non-essential amino acids } \\
\hline Alanine & 27.8 & 24.8 & 23.7 \\
\hline Aspartate/aspartic acid & 36.6 & 31.1 & 44.4 \\
\hline Cysteic acid & 5.4 & 5.6 & 7.9 \\
\hline GABA & 0.2 & 0.4 & 0.1 \\
\hline Glutamate/glutamic acid & 61.4 & 46.3 & 65.6 \\
\hline Glycine & 36.3 & 30.2 & 20.9 \\
\hline Ornithine & 1.0 & 1.5 & 0.8 \\
\hline Proline & 23.8 & 17.5 & 19.8 \\
\hline Serine & 19.6 & 14.1 & 22.1 \\
\hline
\end{tabular}

Analysis performed according to the Waters amino acid protocol. Results for methionine are expressed as methionine sulphone and cystine as cysteic acid

\section{Discussion}

Using an ${ }^{1} \mathrm{H}$ NMR metabolomics approach and OPLS-DA, we found that Arctic charr showed a similar metabolic fingerprint when fed a diet with the majority of the protein from fish meal (diet FM) and a diet with the majority of the protein from zygomycete biomass (diet FZ). This suggests that both feed ingredients have 
comparable physiological effects when fed to Arctic charr. It has previously been shown that Atlantic salmon and rainbow trout have a similar metabolic profile when fed a zygomycete biomass-based diet and a fish mealbased diet (Mydland et al. 2007; Bankefors et al. 2011). In contrast, the commercial diet (ST, with unknown ingredient composition) included in the present study showed a metabolic fingerprint that differed from that of diets FM and FZ. The different metabolic responses in fish fed the diets in the present study may be related to the utilisation of nutrients, in particular dietary protein, and to energy metabolism (Alasalvar et al. 2002; Grigorakis 2007; Fuentes et al. 2010).

Principal component analysis is unsupervised method that is commonly used to identify how one sample differs from another, which variable contributes significant difference and whether those variables are correlated or independent of one another (Wishart 2008). However, in the present study PCA score scatter plots did not indicate any clear trend in metabolite fingerprint related to the different dietary treatments. On the other hand, OPLS-DA analyses revealed differences in metabolic fingerprints in fish fed diets FM, FZ and ST. OPLS-DA, which is a supervised method, has been shown to be helpful in determining and increasing the separation between groups of observations (Wishart 2008). In the present study, OPLS-DA models were fitted including only two diets at a time. The models used singled out diet ST as being different from diets FM and FZ with respect to the metabolic profile found in liver samples from Arctic charr.

The content of EAA was comparable in diets FM and FZ, while the content of histidine, leucine, phenylalanine and valine was higher in diet ST and the content of methionine was lower. There were also differences in the content of NEAA between diets, with higher contents of most NEAA in diet FM compared with diet FZ, and with higher contents of aspartate/aspartic acid, cysteic acid and serine in diet ST compared with diet FM. Glycine and serine are interconverted in the liver by tetrahydrate-dependent hydroxymethyltransferase. These amino acids are involved in sulphur-containing amino acid metabolism, gluconeogenesis and single carbon metabolism in fish (Fang et al. 2002). In the present study, there was a stronger NMR signal intensity for asparagine, creatine, SN-glycero-3-phosphocholine and formate in fish fed diets FM and FZ than in fish fed diet ST. In addition, there was a stronger NMR signal intensity for acetate and choline in fish fed diet FM than in fish fed diet ST, and a stronger NMR signal intensity for lysine, $\beta$-alanine, glucose and inosine in fish fed diet FZ than in fish fed diet ST. A stronger NMR signal intensity for metabolites such as acetate, creatine/creatine phosphate and choline is in line with existing data on Atlantic salmon fed fish meal-based and zygomycete-based diets (Bankefors et al. 2011). The high NMR signal intensity for creatine in diets FM and FZ compared with diet ST in the present study may be related to the energy supply to muscle tissues and may indicate an increase in ATP production.

Choline is involved in various physiological functions such as neurotransmission, betaine synthesis and transportation of lipid molecules, and it acts as a methyl donor in fish tissues (Halver 1989; Mai et al. 2006). Dietary choline has positive effects on weight gain and in the prevention of fatty liver condition in juvenile hybrid striped bass (Griffin et al. 1994). Choline deficiency has been shown to lead to haemorrhagic lesions in the liver and kidney of lake trout, common carp, rainbow trout and chinook salmon (Halver 1957; Ogino et al. 1970; Ketola 1976; Chan 1991).

The high NMR signal intensity for acetate and SN-glycero-3-phosphocholine in Arctic charr fed diet FM compared with diet ST indicates increased activity of the fatty acid metabolic pathway in the former. Increased acetate and SN-glycero-3-phosphocholine in the liver and intestinal tissues has been shown to be related to catabolism of dietary fatty acids in rainbow trout and sea bream (Randall et al. 2013; Robles et al. 2013). In general, fish meal contains high amounts of choline (4.3 g/kg; Barlow et al. 1979), which supports our findings of a higher NMR signal intensity for diet FM compared with diet ST. In the present study, the slightly higher content of crude fat in diet FM than in diet ST cannot explain the difference in NMR signal intensity for acetate between fish fed these two diets, since no difference in NMR signal intensity for acetate was observed between diets FM and FZ, despite the higher content of crude fat in diet FM. However, crude fat analyses do not distinguish between structural lipids, such as membrane lipids, and storage lipids, such as triacyl glycerols. A higher content of tri-acyl glycerol would be expected to result in more acetate being formed. Increased catabolism of ketogenic amino acids (Ile, Leu, Tryp, Lys, Phe) can also result in increased acetate concentrations in the liver. However, the highest contents of these amino acids were found in fish fed diet ST and therefore cannot explain the higher NMR signal intensity for acetate in fish fed diets FM and FZ. The NMR signal intensities for inosine and $\beta$-alanine were higher in fish fed diet FZ than diet ST, which could reflect the high content of pyrimidines and purines in the zygomycete-based diet (Wasternack 1978). $\beta$-alanine 
is normally metabolised to acetyl-CoA through the malonate semialdehyde pathway, which can explain the higher acetate concentration in the FZ group. $\beta$-alanine is involved in antioxidant and buffer activities in fish (Snyder et al. 2008) and elevated levels of $\beta$-alanine are found in tissues due to environmental changes and acute stress (Aragao et al. 2008).

Lysine is an essential amino acid that may be limiting when fish meal is replaced by other protein sources. A limiting dietary lysine content can change protein and energy metabolism in fish (Forster and Ogata 1998). Lysine deficiency can have a negative impact on feed intake, growth and reproductive performance in fish ( $\mathrm{Li}$ et al. 2009). The higher NMR signal intensity for lysine in fish fed diet FZ than in fish fed diet ST may be related to impaired utilisation of lysine in the latter, due to lower digestibility and a more unbalanced essential amino acid profile in diet ST compared with diet FZ. Asparagine is extensively catabolised in the small intestine of fish, and is mostly derived from synthesis by skeletal muscle (Wu et al. 2008). Due to rapid oxidation, and the non-toxic nature of alanine and asparagine, these amino acids are commonly included to balance the nitrogen content in aquafeeds ( $\mathrm{Li}$ et al. 2009). The NMR signal intensity for asparagine was higher in fish fed diet ST than in fish fed diets FM and FZ. This can be explained by higher content (approximately 20 and $40 \%$, respectively) of aspartate and asparagine in diet ST than in diets FM and FZ.

In addition to providing nutrients and energy substrates, zygomycete biomass may have additional value as aquafeed owing to its high chitosan content, since chitosan has the ability to bind fat and act as an emulsifying agent and it has antimicrobial activities (Schulz et al. 1998; Gerasimenko et al. 2004; Arnaz et al. 2009). Chitosan is a non-toxic, biodegradable and biocompatible polysaccharide that is involved in anti-oxidation, promoting permeability across the cell and bio-catalysis processes (Krajewska 1991; Gerasimenko et al. 2004; Arnaz et al. 2009). It is possible that some of the metabolic responses found in the present study could have been related to the physiological effects in the fish. However, further studies are required to investigate whether the inclusion of different levels of zygomycete biomass will affect performance and metabolic responses in Arctic charr.

\section{Conclusions}

Differences in the metabolic fingerprint in liver tissues of Arctic charr fed diets with varying ingredient composition were revealed using an ${ }^{1} \mathrm{H}$ NMR metabolomics approach and OPLS-DA. The metabolic fingerprint was comparable when fish were fed diets with most of the protein from fish meal or from zygomycete biomass. This suggests that both feed ingredients have comparable physiological effects when fed to Arctic charr. In contrast, a commercial diet with unknown ingredient composition showed a metabolic fingerprint that differed from that of the other diets. These different metabolic responses between the commercial diet and the two experimental diets may be related to the utilisation of nutrients, in particular dietary protein, and to energy metabolism.

Acknowledgments This work was supported by a grant from Formas (Swedish Research Council for Environment, Agricultural Sciences and Spatial Planning). The authors are grateful to Dr. Lars Edebo, Department of Clinical Microbiology, University of Gothenburg, Sweden, for producing the zygomycete biomass. Financial support for Rani Abro was provided by Islamic Development Bank.

Conflict of interest The authors declare that they have no competing interests.

Author's contributions TL and AAM conceived and design the study. RA performed the experiments with assistance from AAM. RA, TL and AM analysed the experimental data. RA, AAM, TL and JEL contributed in the writing of manuscript.

Open Access This article is distributed under the terms of the Creative Commons Attribution License which permits any use, distribution, and reproduction in any medium, provided the original author(s) and the source are credited.

\section{References}

Alasalvar C, Taylor kDa, Zubcov E, Shahidi F, Alexis M (2002) Differentiation of cultured and wild sea bass (Dicentrarchus labrax): total lipid content, fatty acid and trace mineral composition. Food Chem 79:145-150 
AOAC (1997) Animal feeds, Chap 4. In: Cunniff PA (ed) Official methods of analysis. Association of Official Analytical Chemists Internation, AOAC, Arlington

Aragao C, Corte-Real J, Costas B, Dinis MT, Conceicao LE (2008) Stress response and changes in amino acid requirements in Senegalese sole (Solea senegalensis Kaup 1858). Amino Acids 34:143-148

Arnaz MA, Mengibar M, Harris R, Panos I, Miralles B, Acosta N, Galed G, Heras A (2009) Functional characterization of chitin and chitosan. Curr Chem Biol 3:203-230

Atherton HJ, Bailey NJ, Zhang W, Taylor J, Major H, Shockcor J, Clarke K, Griffin JL (2006) A combined 1H-NMR spectroscopy- and mass spectrometry-based metabolomic study of the PPAR-alpha null mutant mouse defines profound systemic changes in metabolism linked to the metabolic syndrome. Physiol Genomics 27:178-186

Bankefors J, Kaszowska M, Schlechtriem C, Pickova J, Brannas E, Edebo L, Kiessling A, Sandstrom C (2011) A comparison of the metabolic profile on intact tissue and extracts of muscle and liver of juvenile Atlantic salmon (Salmo salar L.) application to a short feeding study. Food Chem 129:1397-1405

Barlow S (2000) Fishmeal and oil: sustainable feed ingredients for aquafeeds. Global Aquaculture Adv 4:85-88

Barlow SM, Pike IH, Nixon F (1979) Choline content of fish meals from various origins. J Sci Food Agric 30:89-92

Brennan L (2013) Metabolomics in nutrition research: current status and perspectives. Biochem Soc Trans 41:670-673

Bystriansky JS, Frick NT, Ballantyne JS (2007) Intermediary metabolism of Arctic char Salvelinus alpinus during short-term salinity exposure. J Exp Biol 210:1971-1985

Chan MN (1991) Choline. In: Machlin LJ (ed) Hand book of vitamins. Marcel Dekker, New York, pp 537-556

Dijksterhuis J, Samson RA (2006) Zygomycetes. In: Blackburn CdeW (ed) Food spoilage microorganisms. CRC Press, USA, pp 415-436

Edebo L (2009) Zygomycetes for fish feed

Eriksson L, Trygg J, Wold S (2008) CV-ANOVA for significance testing of PLS and OPLS (R) models. J Chemom 22:594-600

Fang YZ, Yang S, Wu G (2002) Free radicals, antioxidants, and nutrition. Nutrition 18:872-879

Fardet A, Canlet C, Gottardi G, Lyan B, Llorach R, Remesy C, Mazur A, Paris A, Scalbert A (2007) Whole-grain and refined wheat flours show distinct metabolic profiles in rats as assessed by a $1 \mathrm{H}$ NMR-based metabonomic approach. J Nutr 137:923-929

Forster I, Ogata HY (1998) Lysine requirement of juvenile japanese flounder Paralichthys olivaceus and juvenile red sea bream Pagrus major. Aquaculture 161:131-142

Fuentes A, Fernandez-Segovia I, Serra JA, Barat JM (2010) Comparison of wild and cultured sea bass (Dicentrarchus labrax) quality. Food Chem 119:1514-1518

Gerasimenko DV, Avdienko ID, Bannikova GE, Zueva OY, Varlamov VP (2004) Antibacterial effects of water-soluble lowmolecular-weight chitosans on different microorganisms. Appl Biochem Microbiol 40:253-257

Gibney MJ, Walsh M, Brennan L, Roche HM, German B, van Ommen B (2005) Metabolomics in human nutrition: opportunities and challenges. Am J Clin Nutr 82:497-503

Griffin ME, Wilson KA, Brown PB (1994) Dietary arginine requirement of juvenile hybrid striped bass. J Nutr 124:888-893

Griffin JL, Muller D, Woograsingh R, Jowatt V, Hindmarsh A, Nicholson JK, Martin JE (2002) Vitamin E deficiency and metabolic deficits in neuronal ceroid lipofuscinosis described by bioinformatics. Physiol Genomics 11:195-203

Grigorakis K (2007) Compositional and organoleptic quality of farmed and wild gilthead sea bream (Sparus aurata) and sea bass (Dicentrarchus labrax) and factors affecting it. Aquaculture 272:55-75

Halver JE (1957) Nutrition of the salmonoid fishes: water soluble vitamins requirements of chinook salmon. J Nutr 62:225-243

Halver J (1989) The vitamins. In: Halver J (ed) Fish nutrition. Academic Press, NY, pp 31-109

Ketola HG (1976) Choline metabolism and nutritional requirement of lake trout (Salvalinus namaycush). J Anim Sci 43:476-477

Krajewska B (1991) Chitin and its derivatives as supports for immobilization of enzymes. Acta Biotechnol 11:269-277

Kristofersson D, Anderson JL (2006) Is there a relationship between fisheries and farming? Interdependence of fisheries, animal production and aquaculture. Mar Policy 30:721-725

Li P, Mai K, Trushenski J, Wu G (2009) New developments in fish amino acid nutrition: towards functional and environmentally oriented aquafeeds. Amino Acids 37:43-53

Mai K, Wan J, Ai Q, Xu W, Liufu Z, Zhang L, Zhang C, Li H (2006) Dietary methionine requirement of juvenile yellow croaker Pseudosciaena crocea. Aquaculture 253:564-572

Moazzami AA, Andersson R, Kamal-Eldin A (2011) Changes in the metabolic profile of rat liver after alpha-tocopherol deficiency as revealed by metabolomics analysis. NMR Biomed 24:499-505

Moco S, Bino RJ, Vorst O, Verhoeven HA, de Groot J, van Beek TA, Vervoort J, de Vos CH (2006) A liquid chromatographymass spectrometry-based metabolome database for tomato. Plant Physiol 141:1205-1218

Mun CW, Cho JY, Shin WJ, Choi KS, Eun CK, Cha SS, Lee J, Yang YI, Nam SH, Kim J, Lee SY (2004) Ex vivo proton MR spectroscopy (1H-MRS) for evaluation of human gastric carcinoma. Magn Reson Imaging 22:861-870

Mydland LT, Landsverk T, Zimonia T, Kiessling A, Edebo L, Storebakken T (2007) Mycelium biomass from fungi (Rhizopus oryzae) grown on spent sulphite liquor from paper pulp as a protein source for rainbow trout (Oncorhynchus mykiss) Abstract European Aquaculture Society. Istanbul, Turkey

Ogino C, Uki N, Watanabe T, Lida Z, Ando K (1970) B vitamin requirements of carp. Bull Jpn Soc Sci Fish 36:1140-1146

Ramadan S, Bonin AM, Kennedy BJ, Hambley TW, Lay PA (2005) Nuclear magnetic resonance analysis of indomethacininduced gastric ulcers. Chem Res Toxicol 18:123-128

Randall KM, Drew MD, Overland M, Ostbye TK, Bjerke M, Vogt G, Ruyter B (2013) Effects of dietary supplementation of coriander oil, in canola oil diets, on the metabolism of [1-(14)C] 18:3n-3 and [1-(14)C] 18:2n-6 in rainbow trout hepatocytes. Comparative biochemistry and physiology. Part B Biochem Mol Biol 166:65-72

Robles R, Lozano AB, Sevilla A, Marquez L, Nuez-Ortin W, Moyano FJ (2013) Effect of partially protected butyrate used as feed additive on growth and intestinal metabolism in sea bream (Sparus aurata). Fish Physiol Biochem 
Sargent JR, Tacon A (1999) Development of farmed fish: a nutritionally necessary alternative to meat. In: Proceedings of the Nutrition Society, pp 377-383

Schulz PC, Rodriguez MS, Del Blanco LF, Pistonesi M, Agullo E (1998) Emulsification properties of chitosan. Colloid Polym Sci 276:1159-1165

Serkova N, Fuller TF, Klawitter J, Freise CE, Niemann CU (2005) H-NMR-based metabolic signatures of mild and severe ischemia/reperfusion injury in rat kidney transplants. Kidney Int 67:1142-1151

Snyder GS, Gaylord TG, Barrows FT, Hardy RW (2008) Carnosine supplementation on an all-plant protein diet for rainbow trout Oncorhynchus mykiss. Abstract of Aquaculture America 08:369

Stella C, Beckwith-Hall B, Cloarec O, Holmes E, Lindon JC, Powell J, van der Ouderaa F, Bingham S, Cross AJ, Nicholson JK (2006) Susceptibility of human metabolic phenotypes to dietary modulation. J Proteome Res 5:2780-2788

Sues A, Millati R, Edebo L, Taherzadeh MJ (2005) Ethanol production from hexoses, pentoses, and dilute-acid hydrolyzate by Mucor indicus. FEMS Yeast Res 5:669-676

Tacon AGJ (2004) Use of fish meal and fish oil in aquaculture: a global perspective. Aquat Resour Culture Dev 1(1):3-14

Wang Y, Tang H, Nicholson JK, Hylands PJ, Sampson J, Holmes E (2005) A metabonomic strategy for the detection of the metabolic effects of chamomile (Matricaria recutita L.) ingestion. J Agric Food Chem 53:191-196

Wasternack C (1978) Degradation of pyrimidines-enzymes, localization and role in metabolism. Biochem Phyiol 173:467-499

Waters NJ, Holmes E, Waterfield CJ, Farrant RD, Nicholson JK (2002) NMR and pattern recognition studies on liver extracts and intact livers from rats treated with alpha-naphthylisothiocyanate. Biochem Pharmacol 64:67-77

Wishart DS (2008) Metabolomics: applications to food science and nutrition research. Trends Food Sci Technol 19:482-493

Wishart DS, Tzur D, Knox C, Eisner R, Guo AC, Young N, Cheng D, Jewell K, Arndt D, Sawhney S, Fung C, Nikolai L, Lewis M, Coutouly MA, Forsythe I, Tang P, Shrivastava S, Jeroncic K, Stothard P, Amegbey G, Block D, Hau DD, Wagner J, Miniaci J, Clements M, Gebremedhin M, Guo N, Zhang Y, Duggan GE, Macinnis GD, Weljie AM, Dowlatabadi R, Bamforth F, Clive D, Greiner R, Li L, Marrie T, Sykes BD, Vogel HJ, Querengesser L (2007) HMDB: the human metabolome database. Nucleic Acids Res 35:D521-D526

Wu G, Bazer FW, Datta S, Johnson GA, Li P, Satterfield MC, Spencer TE (2008) Proline metabolism in the conceptus: implications for fetal growth and development. Amino Acids 35:691-702

Zamani A (2010) Super absorbant polymers from the cell wall of zygomycetes fungi. Doctoral thesis, Department of Biological and Chemical Engineering, Chalmers University of Technology, Sweden 